\title{
Utilization of Cleft Lip and Palate Postoperative Care Guidebook for Caregivers Based on Local Wisdom for Rural Area Communities
}

\author{
Anindita Z. Rasyida', Stanley S. Kamadjaja', David B. Kamadjaja', Taufan Bramantoro², Ni Putu Mira Sumarta' \\ 'Departments of Oral and Maxillofacial Surgery and 'Dental Public Health, Faculty of Dental Medicine, Universitas Airlangga, Surabaya, Indonesia
}

\section{Abstract}

Aim: Indonesia is presumed to be a country with high incidence of cleft lip and palate (CLP). We carried out a cleft mission in Bima, Nusa Tenggara Barat, Indonesia, which is considered as a rural area. Education barrier as well as facilities and socioeconomic status of the rural area residents may contribute as challenges of verbal postoperative care information. CLP postoperative care guidebook and local wisdom may deliver a proper explanation. The aim of this study was to describe the utilization of CLP postoperative care guidebook for caregivers based on local wisdom for rural area communities. Materials and Methods: We provided CLP postoperative care guidebook after cleft and lip surgery. A total of 20 respondents were asked to complete questionnaires with 10 closed-ended questions and 1 open question in two weeks after surgery. We provided the postoperative infection questionnaire to clinicians who carried out patient follow-up care to evaluate potency of infection after surgery. Results: Most of the respondents were parents of patients with CLP (75\%). Potency of postoperative infection was found in $30 \%$ patients, and it showed no correlation in all patients who were treated using this book as a guide (odds ratio $=0.76,[0.06-9.51])$. All respondents $(100 \%)$ used the guidebook as patient's care guide after CLP surgery, and considered it easy to understand. Conclusion: CLP postoperative care guidebook for caregivers based on local wisdom is useful as a health education-promotion media for rural area communities, and it may help in informing early potency of postoperative infection to caregivers.

Keywords: Caregivers, Cleft and Lip Palate, Guidebook, Local Wisdom, Postoperative Care, Rural Area

Received: 21-05-2019, Revised: 08-10-2019, Accepted: 09-10-2019, Published: 25-02-2020

\section{INTRODUCTION}

Cleft lip with or without cleft palate (CLP) is one of the most common human congenital anomalies. Clefts are formed when the right and left side of lip or palate do not fuse completely during fetal growth, causing a gap in between. ${ }^{[1]}$ Worldwide, oral clefts in any form occur in approximately one in every 700 live births, despite the variability driven by socioeconomic status and ethnic background. ${ }^{[2]}$

Indonesia, as a developing country, is presumed to have a high incidence of CLP. A study in West Java, Indonesia showed 1596 CLP patients had been operated in 2011 until 2015. Data distributions were CLP (50.53\%), cleft lip $(24.42 \%)$, and cleft palate $(25.50 \%)$, with most patients of

\begin{tabular}{|l|l|}
\hline \multicolumn{2}{|c|}{ Access this article online } \\
\hline Quick Response Code: & Website: \\
& www.jioh.org \\
\cline { 2 - 2 } & \\
\hline
\end{tabular}

low-socioeconomic status. ${ }^{[3]}$ On the basis of Smile Train Indonesia data (2018), per year $8900+$ newborn babies were born in Indonesia with cleft. ${ }^{[4]}$ This condition leads to many surgeries that were performed either in cleft missions or in cleft surgical centers and hospitals. Optimum surgical results without complications are expected, and proper postoperative care education and information is one of the components for overall procedure.

Address for correspondence: Dr. Ni Putu Mira Sumarta Department of Oral and Maxillofacial Surgery, Faculty of Dental Medicine, Universitas Airlangga, Jawa Timur 60115, Surabaya, Indonesia. E-mail: niputu.mira@fkg.unair.ac.id

This is an open access journal, and articles are distributed under the terms of the Creative Commons Attribution-NonCommercial-ShareAlike 4.0 License, which allows others to remix, tweak, and build upon the work non-commercially, as long as appropriate credit is given and the new creations are licensed under the identical terms.

For reprints contact: reprints@medknow.com

How to cite this article: Rasyida AZ, Kamadjaja SS, Kamadjaja DB, Bramantoro T, Sumarta NP. Utilization of cleft lip and palate postoperative care guidebook for caregivers based on local wisdom for rural area communities. J Int Oral Health 2020;12:80-5. 
Rasyida, et al.: Postoperative care guidebook utilization

We carried out a cleft mission in Bima, Nusa Tenggara Barat, Indonesia, which is considered as a rural area compared to other cities in Indonesia. Education barrier as well as facilities and socioeconomic status of the residents in the rural area may contribute as challenges if the postoperative care information was verbally explained. CLP postoperative care guidebook with illustration and local wisdom (LW) was thought to bridge this barrier to deliver proper explanation; besides, it is handy and easy to understand. The contents of guidebook were an introduction to postoperative care, postoperative care of surgical repair of cleft lip and palate including instruction and wound management, complications related to postsurgical infection, nutrition, and close statement for follow-up. We used simple and daily language, based on LW approach to make it easy to understand, and step-bystep figures and illustrations also. Thus, we may achieve a better outcome for the overall care of the patients with CLP. The aim of this study was to describe the utilization of CLP postoperative care guidebook for caregivers based on LW for rural area communities.

\section{Materials and Methods}

This was a cross-sectional study involving a total sample of 20 respondents that were patient's caregivers. The study was conducted from September 13, 2018 to September 30, 2018 in Bima, West Nusa Tenggara, Indonesia. The respondents were chosen according to the following criteria: those who were older than 16 years of age, those who could read, and those who would be responsible for home caring for patients after surgery. A total of 20 samples were involved in this study. The respondents who participated in this study were given explanation about the procedure, aim, and risk of this study, and signed a consent form. All the procedures were reviewed and approved by the institutional review board with certificate no. 478/HRECC.FODM/VII/2019.

The respondents were asked to complete questionnaires with 10 closed-ended questions and 1 open question in two weeks after surgery. We provided postoperative infection questionnaire to our clinicians who carried out follow-up care in two weeks after surgery to evaluate potency of infection in patients after surgery. Variables that were used to evaluate potency of infection were erythema, temperature, fluid leaking, swollen and smelly wound, pain, and fever. All the respondents had received an explanation pertaining to the study and signed a consent form, which indicates their agreement to participate in this study.

The process of creating this guidebook began with the focus group discussion related to the contents in this guidebook. Researchers had communicated previously with local residents and doctors in that area regarding language barriers, presentation methods, and information needs based on LW since one year before the study. After that, we conducted a cleft mission along with this study in Bima, Nusa Tenggara Barat, Indonesia, providing labioplasty and palatoplasty surgery in October 2018. We described the role and importance of CLP postoperative care guidebook as an education medium based on utilization and content [Figure 1].

Statistical analysis: The acquired data were tabulated and analyzed for correlation using multivariate logistic regression with a level of significance of 0.05 and confidence interval of $95 \%$, by means of Statistical Package for the Social Sciences software, version 16, for Windows (SPSS, Chicago, Illinois).

\section{RESULTS}

A total of 20 respondents participated in this study. More than half of them were female $(65 \%)$, and $55 \%$ of the respondents were older than 30 years of age. The relation of the respondents to the patients with CLP mostly was that of parents $(75 \%)$. Most of the patients treated by respondents (caregivers) were younger than six years of age $(80 \%)$, with the most varied operations that they had undergone were palatoplasty $(47.62 \%)$ and labioplasty $(38.09 \%)$. Only six patients $(30 \%)$ needed further investigation for the potency of postoperative infection [Table 1].

All respondents $(100 \%)$ have been using this guidebook as a patient's care guide after CLP surgery. Besides reading the guidebook by themselves, they also have lent it to others to read. They agreed that this guidebook was easy to understand, and it had complete information relating to postoperative CLP care. This guidebook was also considered attractive, and the language used was understandable according to all respondents $(100 \%)$, but they still thought that local language translation version of this guidebook was needed [Tables 2 and 3]. Variables of postoperative infection potency are described in Table 4. Our evaluation regarding postoperative infection potency in association with patient characteristics showed no correlation in all patients who were treated using this book as a guide (odds ratio $=0.76,[0.06-9.51])$ [Table 5] .

\section{Discussion}

Orofacial clefts constitute correctable condition by means of proper treatment, resulting in a dramatic improvement of function and quality of life. ${ }^{[5]}$ The surgical procedures consist of three steps, namely preoperative, durante operative (the surgery itself), and postoperative care to achieve a proper satisfactory outcome. After surgery, the result cannot be separated from its postoperative treatment. ${ }^{[6]}$ Local medical staffs or nurses have already well trained to the postoperative management and prepared for possible complications. But the hospitalization after surgery are relatively short and home care are needed until the patients got their sutures removed. The relatives or 

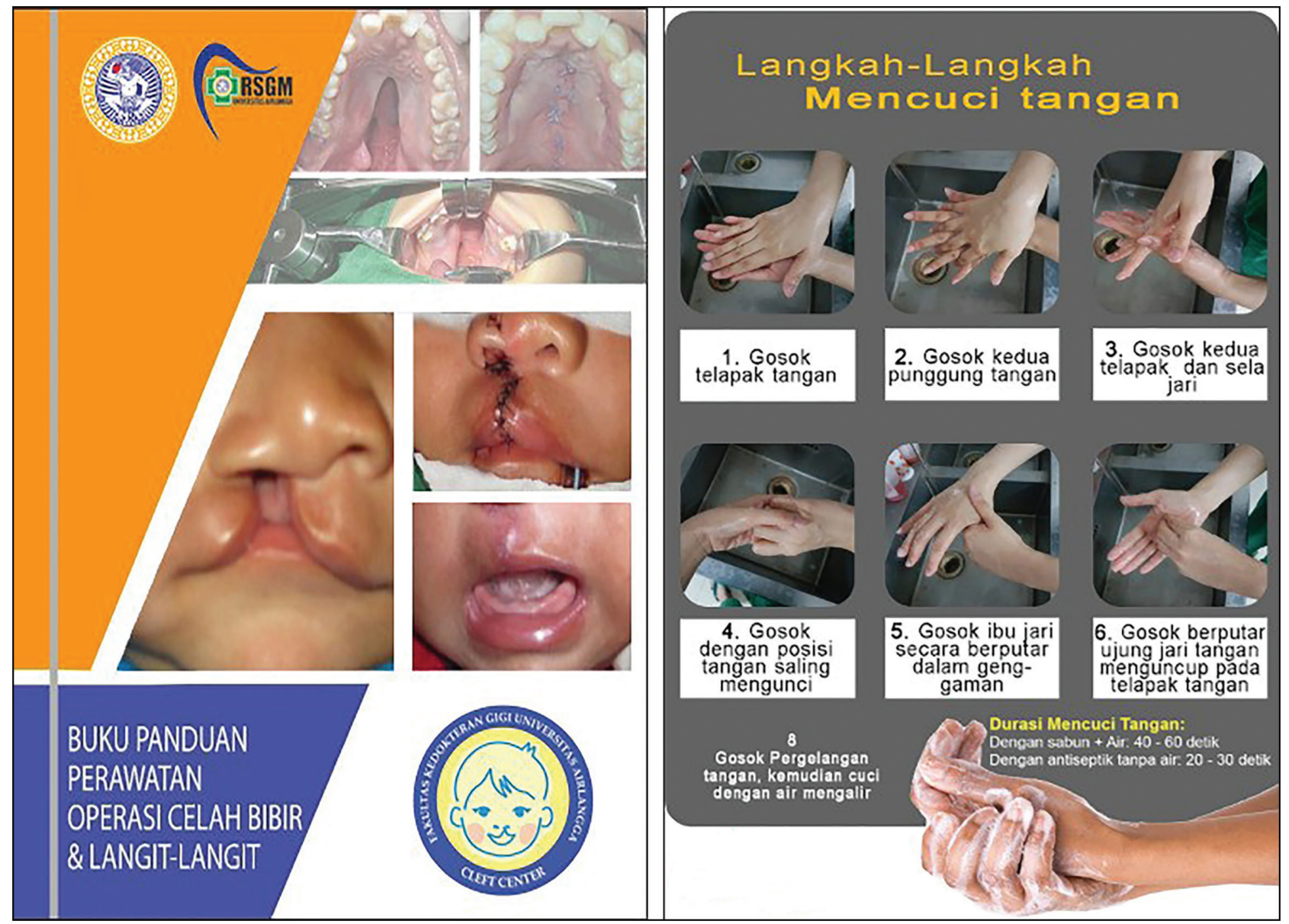

Figure 1: Guidebook's cover and part of the content

accompanying family members of the patients are needed to be informed and integrated into postoperative patient care directly, mostly at home, regarding achieving the best result without complication that may vary from infection till wound dehiscence.

The types of surgery vary from palatoplasty to labioplasty, and those are not simple surgeries, and they need proper postoperative care that is important to be noted by the caregivers. ${ }^{[7]}$ As $80 \%$ of our patients were younger than six years of age, home care after surgery would be handled by family-related people. On the basis of data, it can be summarized that the caregivers or respondents were mostly the patient's parents. It has been proved that parents tend to be concerned and to be involved more in their children's recovery as a caregiver. In this study, the respondents who acted as the caregivers were mostly females.

Postoperative patient education refers to the communication of information about the course of recovery following surgery. It provides patients with the information required to understand their condition, surgery, and recovery; to prevent and manage postsurgical symptoms; and to decrease or reduce hospital readmission, morbidity, and mortality rates. In general, postoperative education covers topics related to medication management, activity performance, nutrition, signs and symptoms of complications, incision care, pain management, and follow-up procedures. ${ }^{[6]}$ The contents of our pocketbook have been already based on this guideline, and all the respondents agreed that this guidebook has complete information and that they used it as a guideline in taking care of patients.

After two weeks of follow-up, we also evaluated the potency of postoperative infection. Patient characteristics based on sex and age showed no correlation in all patients associated with postoperative infection potency. As all the caregivers used the guidebook to help treat the patient, we assumed that the hygiene method used was same in both sex and age categories. Modifying postoperative factors are important to minimize surgical site infection (SSI) ${ }^{[8]}$ Postoperative care education in our book included wound care and sign and symptoms of complications that consisted of early signs of infections. Assessing wounds for SSI after hospital discharge can be carried out by patient's self-reporting, which will be very useful. ${ }^{[9]}$

As with any other medical treatment, CLP correction, its prognosis, and rehabilitation are largely influenced by local sociocultural beliefs and prejudices, and they often determine the need for consultation and medical treatment. 
Rasyida, et al.: Postoperative care guidebook utilization

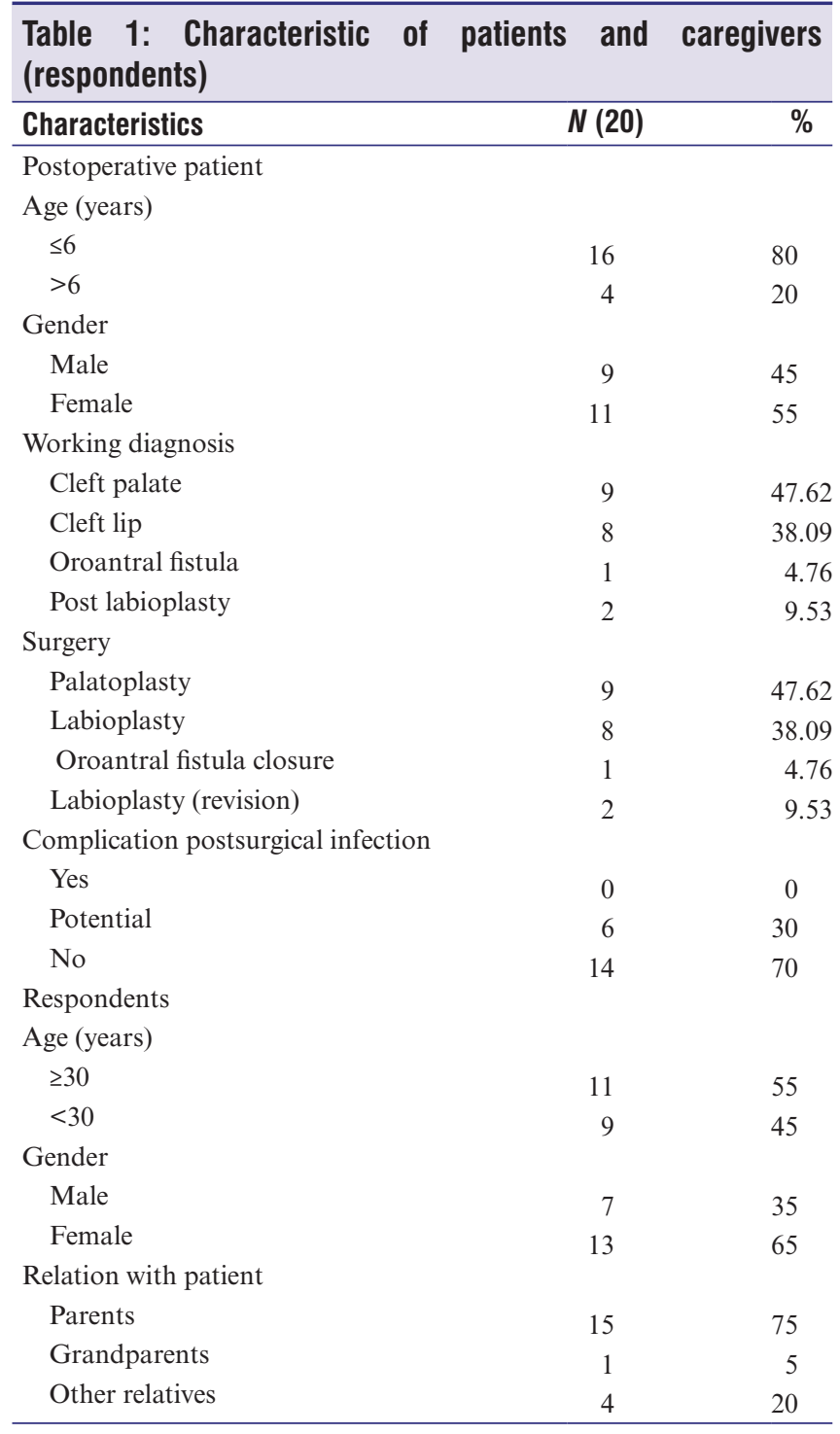

A better understanding of these regional variations in different countries and communities by the cleft team would improve the health-care delivery. ${ }^{[10]}$ That is why, we need LW, which is defined as a dynamic knowledge resource held, evolved and transmitted by a defined population, and integrated with their understanding of surrounding nature and culture. Hence, the guideline we used is not only based on the information after surgery, which needs to be delivered to caregiver, but also through discussion with local residents and doctors in that area regarding language barriers, presentation methods, and information needs based on LW. The respondents claimed that the guidebook was easy to understand, and the language was acceptable even though they still expected local language version.

This guidebook was also a medium to participate in health education in order to reduce complication after surgery by guiding a home care treatment. World Health Organization's health promotion glossary defines health

\begin{tabular}{|c|c|c|}
\hline Variables & $N(20)$ & $\%$ \\
\hline \multicolumn{3}{|c|}{ Utilizations of the book as a patient's care guide } \\
\hline Utilized & 20 & 100 \\
\hline Not utilized & 0 & 0 \\
\hline \multicolumn{3}{|l|}{ Book's user } \\
\hline Respondents & 20 & 100 \\
\hline Others & 0 & 0 \\
\hline \multicolumn{3}{|c|}{ Lending book to other parties } \\
\hline Yes & 20 & 100 \\
\hline No & 0 & 0 \\
\hline \multicolumn{3}{|c|}{ Ease of understanding book content } \\
\hline Easy & 20 & 100 \\
\hline Difficult & 0 & 0 \\
\hline \multicolumn{3}{|c|}{ Completeness of information } \\
\hline Complete & 20 & 100 \\
\hline Not complete & 0 & 0 \\
\hline \multicolumn{3}{|c|}{ Books attractiveness } \\
\hline Attractive & 20 & 100 \\
\hline Not attractive & 0 & 0 \\
\hline \multicolumn{3}{|c|}{ The need to translate to local language } \\
\hline Necessary & 20 & 100 \\
\hline Unnecessary & 0 & 0 \\
\hline
\end{tabular}

education as consciously constructed opportunities for learning, involving some form of communication techniques designed to improve health literacy, which includes improving knowledge and developing life skills that are conducive to individual and community health. Health education is also a vital component of health promotion. Although health education focuses on empowering individuals and communities by providing information and teaching techniques to achieve better health, health promotion emphasizes on environmental and socioeconomic determinants and participatory involvements. ${ }^{[1]}$ The respectful, appropriate use of LW in health promotion increases penetration and longevity of positive behavior change. Collaborations based on mutual respect, flexibility, and trust between the health program organizers, traditional and local practitioners, and the communities being served are the goals for public health physicians in our modern, globalized world. ${ }^{[12]}$

Mode of delivery encompasses the medium and format for providing postoperative education. Medium is the process through which education is delivered. As a medium, face-to-face interaction will be optimized with written resources and/or audiovisual materials. Guidebook of CLP postoperative care comes with detail instruction and picture to deliver information to take care of the patient. All the respondents agreed that this guidebook was attractive and easy to understand. Considering the result that showed all the respondents used the guidebook, we tried to analyze the correlation of the respondents' 
Rasyida, et al.: Postoperative care guidebook utilization

\begin{tabular}{lccccc}
\hline \multicolumn{7}{l}{ Table 3: Crosstab of respondents characteristic with book's utilization and comprehension } \\
\hline Characteristics & Utilized the book (yes) & Book's user & Lending book to others & $\begin{array}{c}\text { Understood the } \\
\text { contents }\end{array}$ & $\begin{array}{c}\text { The needs of local } \\
\text { language translation }\end{array}$ \\
\hline $\begin{array}{l}\text { Age (years) } \\
\quad 30\end{array}$ & $11(55 \%)$ & $11(55 \%)$ & $11(55 \%)$ & $11(55 \%)$ & $11(55 \%)$ \\
$\quad<30$ & $9(45 \%)$ & $9(45 \%)$ & $9(45 \%)$ & $9(45 \%)$ & $9(45 \%)$ \\
Sex & $7(35 \%)$ & $7(35 \%)$ & $7(35 \%)$ & $7(35 \%)$ & $7(35 \%)$ \\
$\quad$ Male & $13(65 \%)$ & $13(65 \%)$ & $13(65 \%)$ & $13(65 \%)$ & $13(65 \%)$ \\
$\quad$ Female & & & & $15(75 \%)$ & $15(75 \%)$ \\
Relation with patient & $15(75 \%)$ & $15(75 \%)$ & $15(75 \%)$ & $1(5 \%)$ & $1(5 \%)$ \\
$\quad \begin{array}{l}\text { Parents } \\
\text { Grandparents }\end{array}$ & $1(5 \%)$ & $1(5 \%)$ & $1(5 \%)$ & $4(20 \%)$ & $4(20 \%)$ \\
$\quad$ Other relatives & $4(20 \%)$ & $4(20 \%)$ & $4(20 \%)$ & & \\
\hline
\end{tabular}

\begin{tabular}{|c|c|c|}
\hline \multicolumn{3}{|c|}{ Table 4: Variables of postoperative infection potency } \\
\hline Wound evaluation & $N(20)$ & $\%$ \\
\hline \multicolumn{3}{|l|}{ Erythema } \\
\hline No & 14 & 70 \\
\hline Little & 6 & 30 \\
\hline A lot & 0 & 0 \\
\hline \multicolumn{3}{|l|}{ Warm } \\
\hline Not at all & 18 & 90 \\
\hline Little & 2 & 10 \\
\hline A lot & 0 & 0 \\
\hline \multicolumn{3}{|l|}{ Fluid leaking } \\
\hline Not at all & 18 & 90 \\
\hline Little & 2 & 10 \\
\hline A lot & 0 & 0 \\
\hline \multicolumn{3}{|l|}{ Swollen } \\
\hline Not at all & 14 & 70 \\
\hline Little & 5 & 25 \\
\hline A lot & 1 & 5 \\
\hline \multicolumn{3}{|l|}{ Smelly } \\
\hline Not at all & 20 & 100 \\
\hline Little & 0 & 0 \\
\hline A lot & 0 & 0 \\
\hline \multicolumn{3}{|l|}{ Painful } \\
\hline Not at all & 15 & 25 \\
\hline Little & 5 & 75 \\
\hline A lot & 0 & 0 \\
\hline \multicolumn{3}{|l|}{ Fever } \\
\hline Not at all & 20 & 100 \\
\hline Little & 0 & 0 \\
\hline A lot & 0 & 0 \\
\hline \multicolumn{3}{|c|}{$\begin{array}{l}\text { Seeking for treatment before follow-up } \\
\text { appointment }\end{array}$} \\
\hline Yes & 1 & 5 \\
\hline No & 19 & 95 \\
\hline \multicolumn{3}{|l|}{ Dehiscence } \\
\hline Yes & 4 & 20 \\
\hline No & 16 & 80 \\
\hline
\end{tabular}

characteristics toward the infection potency. The result showed no correlation between age and gender with the potency of postoperative infection. Thus, we considered that the guidebook is easy to understand by all age-groups as well as genders; therefore, the potency of postoperative infection is low.

We concluded that CLP postoperative care guidebook for caregivers based on LW is useful as a health educationpromotion medium for rural area communities and may help in informing early potency of postoperative infection to caregivers.

\section{Ethical policy and institutional review board statement}

All the procedures were reviewed and approved by the institutional review board with certificate no. 478/ HRECC.FODM/VII/2019.

\section{Data availability statement}

The data of this study will be available on request to the corresponding author by e-mail.

\section{Acknowledgement}

We would like to thank the Direktorat Riset dan Pengabdian Masyarakat (DRPM), Ministry of Research, Technology, and Higher Education, Republic of Indonesia, for supporting this community service in surgical repair of cleft lip and palate patient-based project.

\section{Financial support and sponsorship}

This research received grant of Direktorat Riset dan Pengabdian Masyarakat (DRPM) (No. 1067/UN3/2018), Ministry of Research, Technology, and Higher Education, Republic of Indonesia.

\section{Conflicts of interest}

There are no conflicts of interest.

\section{Declaration of patient consent}

The authors certify that they have obtained all appropriate patient consent forms. In the form the patient(s) has/have given his/her/their consent for his/her/their images and other clinical information to be reported in the journal. The patients understand that their names and initials will not be published and due efforts will be made to conceal their identity, but anonymity cannot be guaranteed. 


\begin{tabular}{|c|c|c|c|c|c|}
\hline Variables & $N(20)$ & Infection potency (\%) & $\mathbf{O R}$ & $\mathrm{OR}(95 \% \mathrm{CI})$ & $P$ value \\
\hline \multicolumn{6}{|l|}{ Sex } \\
\hline Male & 9 & $2(22.22)$ & 1.00 & & \\
\hline Female & 11 & $4(36.36)$ & 1.98 & $0.27-14.61$ & 0.502 \\
\hline \multicolumn{6}{|l|}{ Age } \\
\hline$\leq 6$ & 16 & $5(31.25)$ & 1.00 & & \\
\hline$>6$ & 4 & $1(25.00)$ & 0.76 & $0.06-9.51$ & 0.831 \\
\hline
\end{tabular}

$\mathrm{OR}=$ odds ratio, $\mathrm{CI}=$ confidence interval

$P<0.05$

\section{REFERENCES}

1. Supit L, Prasetyono TOH. Cleft lip and palate review: epidemiology, risk factors, quality of life, and important of classifications. Medical journal of Indonesia. Med J Indones 2008;17:226-39.

2. Brito LA, Meira JG, Kobayashi GS, Passos-Bueno MR. Genetics and management of the patient with orofacial cleft. Plast Surg Int 2012;2012:1-11.

3. Sjamsudin E, Maifara D. Epidemiology and characteristics of cleft lip and palate and the influence of consanguinity and socioeconomic in West Java, Indonesia: A five-year retrospective study. Int J Oral Maxillofac Surg 2017;46:69.

4. Smile Train. Let's change the world one Smile at a time. 2019. Available at: https://www.smiletrainindonesia.org. Last accessed on January 4th, 2019.

5. Ahmed M, Xue Y, Ayub A. Strategies to optimize global cleft care. Designing Strategies for Cleft Lip and Palate Care. InTech; 2017:43-57.
6. Fredericks S, Guruge S, Sidani S, Wan T. Postoperative patient education: A systematic review. Clin Nurs Res 2010;19:144-64.

7. Miachon MD, Leme PL. Surgical treatment of cleft lip. Rev Col Bras Cir 2014;41:208-14.

8. Gaston RG, Kuremsky MA. Postoperative infections: Prevention and management. Hand Clin 2010;26:265-80.

9. Macefield R, Blazeby J, Reeves B, Brookes S, Avery K, Rogers C, et al. Validation of the Bluebelle Wound Healing Questionnaire for assessment of surgical-site infection in closed primary wounds after hospital discharge. Br J Surg 2019;106:226-35.

10. Shirol SS. Sociocultural beliefs and perceptions about cleft lippalate and their implications in the management, outcome, and rehabilitation. J Cleft Lip Palate Craniofacial Anomalies 2018;5:4-5.

11. Kumar Y, Kumar S. Mass media for health education (a study in the state of Rajasthan). Glob Res Acad 2017;1:26-39.

12. Savira EM, Tasrin K. Involvement of local wisdom as a value and an instrument for internalization of public service innovation. Bisnis Birokrasi J 2018;24:1-13. 